\title{
LA ACTIVIDAD DE LOS GRUPOS DE PRESIÓN ANTE EL PODER EJECUTIVO: UNA RESPUESTA JURÍDICA MÁS ALLÁ DEL REGISTRO ${ }^{1}$
}

\author{
RAFAEL RUBIO NÚÑEZ \\ Profesor Titular Derecho Constitucional \\ Universidad Complutense
}

\section{SUMARIO}

I. Los grupos de presión: Denominación, sujetos y definición. II. Informalidad y respuestas normativas. III. La regulación actual del lobby en España. IV. Otras respuestas normativas a la influencia. V. La democratización del lobby

\section{LOS GRUPOS DE PRESIÓN: DENOMINACIÓN, SUJETOS Y DEFINICIÓN}

El lobby es una forma de participación política no institucionalizada. La falta de institucionalización históricamente ha generado problemas que van más allá del alcance a la reputación del lobby, pues han llegado a cuestionar su inserción y su funcionamiento dentro del sistema democrático, así como sus actividades y su acción sobre las instituciones ${ }^{2}$. En los últimos años se ha impulsado tanto la reflexión ${ }^{3}$ como la regulación en países como Polonia (2005/2011), Hungría

1 Trabajo realizado dentro de los proyectos de investigación MINECO «Democracia multinivel: la participación de los ciudadanos y de los entes territoriales en los procesos de decisión pública» (MEC, DER2012-37567) y «Régimen jurídico constitucional del Gobierno 2.0-Open Government. Participación y transparencia electrónicas y uso de las redes sociales por los poderes públicos» (DER2012-37844).

2 La producción científica sobre este tema es escasa en nuestro país hasta la década actual. Podemos destacar entre otros: Ramirez, M. Los grupos de presión en la segunda República Española, Tecnos, 1969. García Pelayo, M. Constitución y grupos de presión en América Latina, UNAM. 1977. Pelegrin, E., El lobby en la Unión Europea, Madrid, ESIC, 1997. XIFRA, Jordi, Lobbying. Como influir eficazmente en las decisiones de las instituciones públicas, Barcelona, Gestión 2000, 1998. FISAS, V., El lobby feroz, Icaria, 1998. RUBIO, R. Los grupos de presión, CEPC, 2003.

3 Sólo en España, tras más de diez años sin publicaciones destacables, en los últimos cinco años han escrito sobre el tema con distintas perspectivas: Fernández Sánchez «La influencia de los grupos de interés en 
(2006/2011), Israel (2008), Francia (2009), México (2010), Eslovenia (2010), Holanda (2012), Austria (2012), Chile (2014), y se encuentra en tramitación en países como Argentina o Colombia. Tanto a través de normas específicas como de normas vinculadas a la transparencia y los mecanismos de participación, la regulación del lobby se ha introducido con fuerza en la agenda normativa mundial ${ }^{4}$.

La transparencia de la actividad de los grupos de presión se ha convertido en una prioridad para políticos y «lobistas», que buscan romper con las asociaciones del término «lobby» con conceptos como la corrupción, el tráfico de interés y la defensa de intereses opuestos al interés general.

El uso de la terminología en referencia a los grupos de presión no es inocente, $y$, aunque la doctrina suele distinguir matices en el uso de uno u otro término $^{5}$, a la hora de la verdad, los distintos conceptos suelen acabar confundidos, afectando al debate. Así, de manera general, el lobby es aquel enemigo del interés general que busca imponer sus pretensiones económicas o sociales, como por ejemplo «el lobby católico vs el lobby LGTB». Jugando con algunos títulos de libros publicados sobre este sector, podemos ver que «los gigantes asesinos» 6 que han puesto «el Congreso en Venta» ${ }^{7}$ por «un billón de dólares» ${ }^{8}$ conducirán a la «Destrucción de la Democracia» ${ }^{9}$ como consecuencia de una enfermedad poderosa y múltiple, la «demosclerosis» ${ }^{10}$. Mientras, aquellos que comparten ciertos puntos de vista de forma mayoritaria son siempre «la gente», «la sociedad civil en acción», e incluso «los sin poder que reclaman su momento» que, según este mismo modo, lo harían «uniendo a la gente con el gobierno» ${ }^{11}$, y

el proceso legislativo socioeconómico: el caso del sector asegurador» PPU, 2012. VVAA «El Lobby en España ¿Asignatura Pendiente? Algón, 2014. Villoria, M. «Una evaluación del lobby en España: Análisis y propuestas», Transparencia Internacional, 2014. PONCE, J. «Negociación de normas y Lobbies», Thomson Reuters Aranzadi, 2015. Molins, J; MuÑoz, L. y MedinA, I. «Los grupos de interés en España. La influencia de los Lobbies en la política española», Tecnos , 2016. Y un par de capítulos en «La corrupción en España. Ámbitos, causas y remedios jurídicos» Villoria, M. Gimeno, J. M. y Tejedor, J. Atelier Libros, 2016. Además se han defendido distintas tesis doctorales, por ejemplo: Cordova, D. «La regulación de los Lobbies en Latinoamérica», UCM, 2016. HernÁNDEZ AGUADO, I. «El buen gobierno de la sanidad: Las influencias debidas e indebidas en la formulación de políticas de salud «, UCM, 2017. ELGUERO, J.M. Lobby y grupos de presión: análisis regulatorio y estudio en el sector asegurador, UCM, 2017.

4 Principles for Transparency and Integrity in Lobbying. Disponible en: http://www.oecd.org/gov/ ethics/oecdprinciplesfortransparencyandintegrityinLobbying.html

5 Para las diferencias entre ambas denominaciones, y otras habituales para designar a los sujetos de la influencia política, nos remitimos a Rubio, R. Los grupos de presión, Madrid, CEPC, 2003. Pág. 178 y ss.

6 Pertschuk, M., Giant Killers, New York, Norton, 1986.

7 Lewis, Ch., The Buying of the Congress: how Special Interests Have Stolen your Right to Life, Liberty, and the Pursuit of Happiness, New York, Avon Books, 1998.

8 Godwin, K., One Billion Dollars of Influence: the Direct Marketing of Politics, Chatham, NJ, Chatham House Publishers, 1988.

9 Bennetr, J. y Dilorenzo, Th., Destroying Democracy: How Government Funds Partisan Politics, Washington, DC, Cato Institute, 1985.

10 Rauch, J., Demosclerosis: the Silent Killer of American Government, New York, Times Books, 1994.

11 Rothenberg, L. S., Linking Citizens to Government, New York, Cambridge UP, 1992. 
anunciando que están «presionando para el cambio social» ${ }^{12} \mathrm{y}$ «el bien común» ${ }^{13}$ : «lobbying for people» ${ }^{14}$.

Aunque, según parte de la doctrina que distingue entre lobbies y grupos de presión, los lobbies son aquellas organizaciones que desarrollan su actividad de influencia en representación de otros a cambio de una contraprestación económica por sus servicios, lo cierto es que, al referirnos a los lobbies, nos enfrentamos a una diversidad de empresas y organizaciones que actúan por cuenta propia o en representación de terceros, sin recibir, en muchos casos, remuneración de ningún tipo.

A la confusión terminológica se une la creciente pluralidad de los actores que desarrollan acciones de influencia, cada vez más numerosos y diversos, y que van mucho más allá del mundo empresarial, alcanzando a los think tanks, la academia, o los grupos de la sociedad civil que no dudan en adoptar estas técnicas en defensa de los intereses defendidos ${ }^{15}$.

El problema surge a la hora de encontrar una denominación común para todos aquellos que realizan actividades de presión e influencia. Empresas y organizaciones parecen no ponerse de acuerdo y una mirada rápida a los departamentos que ejercen la participación política no institucionalizada deja una lista casi infinita de nomenclaturas: Lobby; cabildeo; Legal $\mathcal{E}$ Corporate Affairs; relaciones institucionales; relaciones públicas; Public Affairs; Government Affairs; Legislative Affairs; relaciones institucionales; asuntos públicos; diplomacia corporativa, etc. Lo mismo ocurre con la forma jurídica que adoptan estos grupos: ONG, PAC, think tanks, asociaciones, fundaciones, empresas, uniones o confederaciones sectoriales-regionales, empresas, grupos empresariales, agrupaciones ciudadanas, e incluso, hasta movimientos sociales, lo que dificulta mucho su identificación, especialmente de cara a su regulación.

De este modo, afrontar el debate conceptual en este caso adquiere una importancia mayor de lo habitual. Ante la diversidad de denominaciones y de actores para ajustar nuestro objeto de estudio, se propone una definición de grupos de presión como «toda unión de individuos, autónoma y organizada, que lleva a cabo acciones para influir en el poder (...) en defensa de unos intereses comunes» ${ }^{16}$. Esta definición resulta suficientemente amplia para cubrir el objeto de nuestro estudio, y abarcaría las funciones que desarrolla la actividad de presión e influencia, tales como la representación de sus miembros frente al Gobierno; el ofrecimiento de un canal de participación política al margen de las elecciones; la aportación de conocimiento a sus miembros sobre la situación del proceso

12 Richan, W., Lobbying for Social Change, New York, Haworth Press, 1996.

13 Mc Farland, A. S., Common Cause: Lobbying in the Public Interest, Chatham, NJ, Chatham House Publishers, 1984.

14 Berry, J., Lobbying for the People. The Political Behavior of Public Interest Groups Princenton, NJ, Princenton University Press, 1977.

15 Alemanno, A. Lobbying for Change, Iconbooks, Londres, 2017.

16 Rubio NúÑez, R., Los grupos de presión, Madrid, CEPC, 2003. 
político; el diseño de la agenda pública y el seguimiento de la actividad del gobierno para comprobar el estado de sus intereses ${ }^{17}$.

A efectos de este trabajo utilizaremos de manera indistinta los términos grupos de presión, grupos de interés y lobby.

\section{INFORMALIDAD Y RESPUESTAS NORMATIVAS}

El ejercicio de la influencia se produce siempre en un doble plano. Por un lado el ejercicio de la influencia a través de la participación no estructurada, fuera o dentro de los momentos establecidos para ella en los distintos procedimientos administrativos, y por otro a través de modelos institucionalizados que generan espacios para la interacción entre grupos y poderes públicos, a través de órganos de participación institucional.

En ambos casos la acción de los grupos de presión no se canaliza necesariamente a través de los mecanismos formales previstos por el ordenamiento jurídico. Esta actividad informal de los grupos de presión «se produce al margen de los mecanismos formalizados de actuación administrativa y emplean instrumentos de dirección que actúan sobre todo influenciando o motivando, sin tener un carácter formalizado» ${ }^{18}$.

Es cierto que estas actuaciones se llevan a cabo de manera informal, pero eso no significa que sea indiferente para el Derecho ${ }^{19}$. Las actividades informales están también sujetas a los principios jurídicos constitucionales aplicables a cualquier actividad administrativa, aunque, como advierte Cerrillo, las instituciones tradicionales de garantía propias del Estado de Derecho no se han diseñado para ser útiles contra la actividad informal ${ }^{20}$. De este modo la actividad de negociación de regulaciones en el ámbito del poder ejecutivo se produce de modo informal, «a la sombra del derecho», pero no necesariamente contra el Derecho, pues informal e ilegal son dos conceptos distintos. Como recuerda Ponce ${ }^{21}$ aunque informalidad no es equivalente a ilegalidad, «el proceso decisorio informal lleva consigo también el peligro de desatender $-\mathrm{y}$, por ende, recortar- las posiciones jurídicas de terceros», lo que hace que tal proceso lleve «el peligro de una posible tendencia hacia una actuación administrativa ilegal» ${ }^{22}$.

17 Berry, J. M. Lobbying for the People. The Political Behavior of Public Interest Groups Princenton, NJ, Princenton University Press, 1977.

18 Cerrillo, A. «La participación en los órganos colegiados en la administración en red» en Revista Vasca de Administración Pública, núm. 90. Mayo-Agosto 2011. Pág. 84

19 Gordillo, A., «La Administración paralela», Civitas, 1982.

20 Cerrillo, A. «La participación en los órganos colegiados en la administración en red» en Revista Vasca de Administración Pública, núm. 90. Mayo-Agosto 2011. Pág. 87

21 Ponce, J. «Negociación de Normas y Lobbies», Thomson Reuters Aranzadi, 2015. Pág. 39

22 SCHulze-Fielitz, H., «¿Informalidad o ilegalidad de la actuación administrativa?», Documentación Administrativa, núm. 235-236 (julio-diciembre 1993), pp. 98 y 99. 
Así lo denuncia el informe de Transparencia Internacional sobre el estado del lobby en España que señala:

«(...) el principal riesgo que se identifica es la opacidad en la toma de decisiones y, tal vez, la falta de consideración igualitaria de todos los intereses de todas las partes interesadas en el proceso de desarrollo normativo ${ }^{23}$. En este sentido, se observa que la ausencia de regulación de la práctica del lobby ha podido provocar que se regule escuchando más a unos que a otros» ${ }^{24}$.

De ahí la necesidad de adoptar los mecanismos necesarios para evitar las amenazas que este tipo de actividades pueden suponer a la seguridad jurídica, la reserva de ley o la igualdad. Establecer normas que regulen la actuación de los grupos de presión, y hacerlo, como destaca Schmidt-Assmann, saliendo de un modelo regulatorio meramente limitativo o prohibitivo, incorporando a la regulación procedimientos que permitan salvar la flexibilidad de la informalidad y compatibilizarla con la buena administración y la garantía de los derechos de los participantes en la negociación y de los terceros ${ }^{25}$. Como señala Cassese, «la libertad crece en los intersticios del procedimiento ${ }^{26}$ y sólo podrá ser así tratando que estas prácticas y procedimientos informales puedan llegar a alcanzar soluciones que tengan en cuenta todos los intereses afectados ${ }^{27}$. En resumen, garantizar la transparencia y la participación de todos los actores representantes de intereses.

\section{a) Regulación general, regulación específica y autorregulación.}

Ante esta compleja realidad, la respuesta normativa ha adoptado distintas posturas. Desde finales del siglo XVIII se ha planteado el papel de estos grupos en el sistema democrático. Ya en 1780, Madison alertaba de que «existen dos formas de paliar las consecuencias de una facción: la primera, eliminando sus causas; la segunda, controlando sus efectos». Desde entonces, la necesidad de regular los grupos de presión se ha ido imponiendo como consecuencia de su protagonismo y su visibilidad en la vida política. Siguiendo con la lógica kelseniana de la «democracia real», la existencia e importancia transcendental de los grupos de

23 En este sentido el Tribunal Supremo (16.9.2003, RJ 2003, 6836) no considera que exista nada ilegal en que la Administración se reúna con unos y no con otros.

24 Villoria, M. (dir) y Revuelta, A. (coordinadora) (2015), Una evaluación del lobby en España: Análisis y propuestas. Transparencia Internacional España. Pág. 30

25 Agudo, J., «Actuación material e informalidad. El ejemplo de la concertación con la Administración», Revista Aragonesa de Administración Pública, núm. 41-42, 2013, pp. 123 y ss.

26 CAssese, S., «New Paths for administrative law: A manifesto», International Journal of Constitutional Law (2012), 10 (3), pág. 4.

27 Schdmidt-Assmann, E., La Teoría General del Derecho Administrativo como sistema , INAP-Marcial Pons, 2003, Madrid. 
presión, algo que para García Pelayo «no solo es un hecho, sino que es parte de un mecanismo necesario para el funcionamiento de la sociedad y del Estado de nuestro tiempo ${ }^{28}$, haría necesaria su inserción dentro del sistema ${ }^{29}$. De esta manera, se trata de compaginar su actividad legítima con las garantías de independencia y salvaguarda del interés general de los poderes públicos.

En este asunto nos encontraríamos ante la paradoja que aquellos que más reacios son a la actuación de los grupos de presión son los menos partidarios de regularlo, en una actitud que combina la «estrategia del avestruz» con el cervantino «peor es meneallo» ${ }^{30}$. Mientras, son aquellos que observan con mayor interés la participación de estos grupos en la vida política, incluidos los sujetos de la misma, los que tratan de impulsar su regulación ${ }^{31}$.

De esta manera al abordar la regulación del lobby podemos observar hasta cuatro modelos centrados en el sujeto activo de la presión:

El primer modelo comprende la no regulación, lo que conlleva que los actores que desarrollan actividades de influencia y su actuación quede sometida a la normativa general que puede afectar a este tipo de actividades como el tráfico de influencias ${ }^{32}$, las incompatibilidades, las puertas giratorias, el conflicto de intereses, etc. Los argumentos que sostienen la defensa de este modelo son variados, pero fundamentalmente se apoyan en dos ideas principales: por un lado, se piensa que la respuesta frente a la toma de decisiones fraudulenta por parte de los funcionarios públicos es suficiente para abarcar esta realidad y hace innecesario regulaciones específicas; por otro lado, se considera que regular los grupos de presión implicaría otorgarles carta de naturaleza dentro del sistema democrático.

El problema de este modelo podría resumirse con las conocidas palabras hipotéticamente pronunciadas por Galileo Galilei, «eppur si muove». Es decir, la actuación de los grupos es generalizada, y reconocida como tal, tanto por los poderes públicos, como por las empresas ${ }^{33}$, y sus modos de actuar presentan unas

28 García Pelayo, M. Constitución y grupos de presión en América Latina, UNAM. 1977. Pág. 22

29 Kelsen, H. Esencia y valor de la democracia. Labor. Barcelona. 1977. Pág. 43

30 Cervantes, Miguel de. Don Quijote de la Mancha. Primera parte. Capítulo XX.

31 Una muestra de este fenómeno puede observarse en los debates constituyentes españoles. Tras el voto particular introducido por D. Manuel Fraga (Boletín Oficial de las Cortes, num. 44, de 5 de enero de 1978, págs. 698-699) se plantea un debate que se celebra en la sesión número 15 de la Comisión de Asuntos Constitucionales y Libertades Públicas,, 2 de junio de 1978 y está recogida en el Diario Sesiones.

http://www.congreso.es/public_oficiales/L0/CONG/DS/C_1978_080.PDF (págs. 2910-2914)

32 En el caso español, como recuerda PONCE «la tipificación del tráfico de influencias se realiza en los artículos 428-430 del Código penal», artículos que, como ya advertíamos en 2003 hacen de difícil aplicación este tipo penal. La último reforma de 2015, que afecta también al ámbito de la negociación de normas jurídicas, ha pretendido dar respuesta a este problema aún no sabemos con qué éxito.

33 Según una encuesta de Burson-Marsteller y Cariotipo en España el 56\% de los políticos entrevistados afirma hablar con lobistas y lo hace porque es su obligación atender a quien se lo requiere. Además el $86 \%$ considera que el lobby contribuye al desarrollo político. Por el lado de los grupos de presión, según un estudio encargado por la Asociación de Profesionales de las Relaciones Institucionales (APRI) y realizado por la Escuela Internacional de Comunicación (2017), todas las grandes empresas (100\%), la práctica totalidad de asociaciones profesionales (98\%), el $90 \%$ de ONGs o el $80 \%$ de los Sindicatos realizan estas actividades para 
peculiaridades, que, de no afrontarse de manera específica, pueden generar situaciones de abuso.

Unido habitualmente a este modelo de regulación, que hace referencia a la regulación no específica, se encuentra el segundo modelo, que opta por la autorregulación. Según el modelo de autorregulación, correspondería a las asociaciones profesionales de lobistas establecer los requisitos necesarios para ejercer la profesión. El modelo de autorregulación ha tenido peso, de manera autónoma, en regulaciones de tradición anglosajona, y durante los últimos años se ha convertido en un modo de actuación complementario al de registro.

Este modelo el del registro, cuyo origen se encuentra en Estados Unidos, es el más extendido entre los países que optan por una regulación específica y sería el tercer modelo. Sus elementos centrales habitualmente combinan el establecimiento de un registro con un código de conducta para los grupos de influencia y sus miembros. Es el modelo regulatorio habitual desde 1946 (Estados Unidos) y es el que ha adoptado, tanto la Unión Europea ${ }^{34}$, como la OCDE en sus recomendaciones a los países miembros ${ }^{35}$. A día de hoy, lo han asumido con ligeras modificaciones países como Australia (1983), Canadá (1989), Polonia (2005), Hungría (2006), Israel (2008), Francia (2009), Eslovenia y México (2010), Austria y Holanda (2012), Chile y Reino Unido (2014).

Este tipo de regulaciones tiene su principal problema en la definición del sujeto activo y el establecimiento de la obligatoriedad de registro, que podría colisionar con los derechos de participación política, o el establecimiento de incentivos suficientes para el registro, en caso de que este sea voluntario.

El último modelo regulatorio implica el ejercicio de control sobre los poderes públicos. La base de este modelo serían las agendas públicas. De esta manera, serían los poderes públicos los obligados a informar sobre las personas de las que han recibido acciones de influencia, así como del contenido de las mismas. La peculiaridad de este modelo, también de regulación específica, sería su concentración en la actividad y la atención al sujeto pasivo, el poder público. Este modelo es novedoso y ha empezado a ser aplicado recientemente por Chile (2014) ${ }^{36}$, que establece un sistema de registro en el que cualquier autoridad pública debe dar cuenta, tanto de las audiencias de lobby, como de los viajes realizados y los donativos recibidos. La suma de toda esta información, disponible en http://www. infolobby.cl/ en formato reutilizable, va construyendo una base de datos en la que

influir en la regulación de las actividades sectoriales (98\%) y mejorar el entorno de negocio de las compañías $(94 \%)$.

34 El Parlamento Europeo estableció su registro en 1995 (tal y como establecía el artículo 9.2 de su reglamento), la Comisión hizo lo propio en 2008. Años después, 2011, se unificó el registro en el Registro de Transparencia Europea, en el que el Consejo es un mero observador. Actualmente se encuentra en marcha una reforma que, entre otras cosas, plantea la adhesión del Consejo a este Registro.

35 http://www.oecd.org/corruption/ethics/Lobbying-Brochure.pdf

36 Ley Núm. 20.730 regula el lobby y las gestiones que representen intereses particulares ante las autoridades y funcionarios. (https://www.leychile.cl/Navegar?idNorma=1060115) 
es posible controlar las influencias que se han ejercido sobre cualquier ley o decisión pública.

Tras sus primeros años, las críticas a esta ley, que de momento es única en su modelo, tienen que ver con la existencia de una falla legal que permite a las autoridades no registrar aquellas reuniones celebradas a petición propia, aunque es un aspecto que no sería difícil de solucionar. Otra crítica, más de fondo, señala el exceso de carga administrativa que esta ley genera en las autoridades públicas, al trasladar el peso de los procesos burocráticos de las organizaciones de influencia a las autoridades.

En resumen, podemos decir que, aunque el modelo de la regulación no específica es mayoritario en el mundo, por la mera ausencia de legislación específica, en los últimos diez años se está produciendo una incorporación progresiva de distintos países al modelo regulatorio específico.

Esta regulación creciente se centra en la transparencia a través del registro de los grupos de presión. La gran mayoría se centra en la transparencia del sujeto activo y los recursos que emplean en estas actividades, a través de los informes periódicos en los que deben dar cuenta, al menos, de las políticas públicas en las que han tratado de influir, y de aquellos actores políticos con los que han contactado con este fin.

Esta ha sido, en nuestra opinión, la causa de gran parte de los problemas regulatorios del lobby desde la primera ley estatal norteamericana ${ }^{37}$, la Federal Regulation of Lobbying Act of $1946^{38}$, hasta los distintos intentos de regulación en la Unión Europea ${ }^{39}$. De este modo, se produce una paradoja por la que, como consecuencia de la dificultad de definir el lobby como sujeto de la regulación, la apuesta por la transparencia de los lobbies puede no ser la manera más eficaz de lograr la transparencia del ejercicio del lobby.

De ahi que sea necesario buscar otras respuestas. Estas pueden centrarse tanto en las actividades desarrolladas, como en el sujeto pasivo de la presión, o en ambas.

b) Las acciones de influencia.

Para intentar dar respuesta a una cuestión tan compleja es necesario tratar de adoptar perspectivas diferentes. En este trabajo, se propone centrar la atención

37 http://www.gao.gov/products/T-GGD-91-56

38 United States v. Harriss, 347 U.S. 612 (1954) salvó la constitucionalidad de la ley pero restringió su aplicación de una manera sustancial.

39 La regulación del registro ha sufrido cambios continuos en los últimos años. En 1995 se estableció el Registro del Parlamento Europeo, en 2008 la Comisión estableció su propio registro y ambos se unificaron en 2011. Actualmente se encuentra sometida, de nuevo, a revisión, con una propuesta que plantea hacer el registro unificado obligatorio e incorporar al Consejo al sistema de transparencia. 
sobre las acciones de influencia que los grupos de presión desarrollan sobre los distintos actores que participan en el proceso de toma de decisiones públicas, siguiendo con la definición de Transparencia Internacional, y no en el perfil de los que las llevan a cabo, (o al menos no exclusivamente).

Vamos a detenernos brevemente en la naturaleza de estas actividades. El primer punto sería considerar el objetivo común de este tipo de acción: la influencia en los poderes públicos. De este modo, encontramos, por ejemplo, que esta intención forma parte habitual de la definición del lobby. Por ejemplo, la ley 19/2014 de Transparencia de Cataluña habla de «actuaciones con finalidad de influir en la orientación de las políticas públicas o en procesos de toma de decisiones $»^{40}$. Así lo señala también la definición utilizada por Transparencia Internacional que define el lobby por su «finalidad de influencia en la toma de decisión pública». El objetivo de influencia definiría entonces de manera clara el campo en el que se debería mover la regulación. Esta influencia no solo suele ser una forma eficaz, normalmente la más eficaz, de alcanzar sus objetivos por parte de las organizaciones, sino que suele resultar imprescindible. Esto conlleva que todas las organizaciones que pretenden cumplir con su función traten de lograr ejercer la influencia, de manera directa o a través de terceros, y que este elemento no nos permita establecer distinciones entre ellas, de cara a una propuesta normativa.

El segundo punto es la naturaleza de los intereses defendidos, otro de los elementos fundamentales que están detrás del debate sobre la regulación del lobby. Existe una tendencia natural a distinguir entre los intereses privados y el interés general, como recoge, por ejemplo, la definición de la Asociación Profesional de las Relaciones Institucionales (APRI) que se refiere al «traslado de intereses privados a las instituciones públicas». De esta manera, se trataría de diferenciar entre la defensa de intereses privados, que sería el objeto del lobby, y la defensa del interés público, propio de la participación política. Desde nuestro punto de vista, se trata de una distinción tan habitual como inadecuada para afrontar la regulación de este fenómeno. En primer lugar, porque cualquier decisión, especialmente las legislativas, afectan a la sociedad. No en vano, el carácter general de las mismas es uno de sus elementos distintivos y, en el día a día, ningún grupo, sea de la naturaleza que sea, defiende su interés como algo que provoca beneficios exclusivos para el propio grupo, sino que al desarrollar las actividades de lobby siempre se tratará de buscar el enfoque de interés público de la posición defendida, lo que haría difícil establecer un filtro en primer término. Si a esto se le une que, en la propuesta, diseño e implementación de políticas públicas los distintos actores suelen defender intereses contrapuestos, resulta discutible que en una sociedad pluralista se puedan establecer discriminaciones a la participación

40 Ley 19/2014, de 29 de diciembre, de transparencia, acceso a la información pública y buen gobierno disponible $(\mathrm{GdC})$ en: http://noticias.juridicas.com/base_datos/CCAA/542867-1-19-2014-de-29-dic-ca-cataluna-transparencia-acceso-a-la-informacion-publica.html 
política a priori, en función de una identificación previa de sus intereses como generales (algo habitual, por ejemplo, en las ONG) o particulares (como podrían ser las empresas). Esto nos conduce a una segunda fase de la reflexión, que tendería a identificar el interés general con la ausencia de ánimo de lucro, atribuyendo un extra de legitimidad a aquellos que defienden causas en las que no hay un interés lucrativo directo, algo que, resulta aventurado al identificar el ánimo de lucro con el interés personal y, lo que es más significativo, la ausencia del mismo con el interés general.

Nosotros pensamos que cualquier grupo, asociación, empresa o ciudadano que pretende influir ante los poderes públicos deberá obtener una misma acogida por parte de la regulación. De este modo, serán los objetivos defendidos, una vez escuchados, y las actividades realizadas las que determinarán hasta qué punto la intervención de esos grupos sirve para mejorar el resultado del proceso de toma de decisiones, adecuándolo a la realidad del asunto y al punto de vista de afectados e interesados o, por el contrario, lo perjudica introduciendo un elemento de desigualdad en un sistema democrático que se basa en la representación.

De esta manera, desechado el criterio de la finalidad, por ser común, y el de la naturaleza del interés defendido, por resultar insuficiente como elemento determinante de la regulación, consideramos interesante explorar la vía del tipo de acción. En línea con la definición de Transparencia Internacional, identificamos el lobby con «la acción sobre los distintos actores que participan en el proceso legislativo», y nos centraremos en la actividad, incluyendo a todo aquel que realiza estas actividades, incluidos los particulares, cuyos grupos, como en el caso de la regulación irlandesa, estarían sujetos también a los requisitos de transparencia.

Estas actividades están basadas fundamentalmente en la «comunicación directa o indirecta». La acción del lobby es fundamentalmente una labor que tiene en la información, personal o a través de la opinión pública, su materia prima fundamental. De ahí que todas sus acciones, realizadas de manera continua, velando por promover un entorno político favorable para los intereses defendidos; o con objetivos concretos, a través de campañas con inicio y fin, tengan como eje la información, su consecución y su transmisión a los distintos actores que participan, directa o indirectamente, en las decisiones públicas.

Durante mucho tiempo, el lobby se ha caracterizado exclusivamente por facilitar el acceso a los decisores públicos, contando entre sus filas con antiguos políticos o antiguos funcionarios que garantizaban ese acceso, como parte fundamental de sus servicios, pero hace tiempo que eso empezó a cambiar. Hoy las actividades de los grupos de influencia podrían dividirse fundamentalmente en cinco tipos: aquellas vinculadas a la creación de una posición favorable, las de consecución de información, las que se refieren a la relación con los decisores, aquellas que tratan de crear un clima de opinión pública favorable y las que buscan la movilización social.

La lista de actividades de influencia a día de hoy es prácticamente infinita y abarca desde las actividades de transmisión de información directa, como la 
elaboración de análisis regulatorios, estudios e informes, la negociación, la participación en comisiones parlamentarias o grupos de trabajo, las intervenciones públicas, etc., hasta otras actividades como el seguimiento legislativo, el acceso a los parlamentarios, la creación de una red de contactos, el mantenimiento de relaciones profesionales con decisores (que cuenta con mecanismos propios de las relaciones humanas básicas como un mensaje de interés, una llamada telefónica de preocupación, un cruce casual, una comida....), la relación con medios de comunicación y la opinión pública ${ }^{41}$, la financiación de congresos y reuniones e incluso de informes técnicos, la gestión de la reputación, el establecimiento de alianzas, la sensibilización ${ }^{42}$, la movilización ciudadana, etc. Además, encontramos otras que, aunque no coincidan en el tiempo, pueden influir en los procedimientos normativos predisponiendo la voluntad de los actores que participan en la toma de la decisión, como la financiación de campañas electorales, las incompatibilidades y las puertas giratorias. Se trata de actividades que, como señalan Revuelta y Villoria, «pueden ser legales, pero son empleadas para crear políticas o leyes que favorecen intereses económicos privados y dañan al interés general» y pueden provocar la «captura de políticas», definida como «el control por grandes grupos de interés de áreas de políticas dentro de un Estado» ${ }^{43}$.

Todas estas actividades pueden desarrollarse en momentos distintos del proceso que siguen las políticas públicas y pueden entrañar riesgos de corrupción o malas prácticas relacionados con el lobby, desde la formulación, a la toma de decisión y la implantación de la política. Como señalamos en Villoria (2015) algunos ejemplos de prácticas y actividades que pueden suponer riesgos de corrupción o prácticas no éticas son ${ }^{44}$.

41 Aunque tradicionalmente las acciones de lobby preferían permanecer al margen de la opinión pública, hoy en la sociedad de la información la sociedad reclama a la política y a los políticos más transparencia, más legitimidad (Gutiérrez-Rubi, A., La política vigilada, Barcelona, Editorial UOC, 2011), y estas nuevas dinámicas de la política exigen que las actividades que buscan incidir en la vida política se desarrollen de cara a la opinión pública y cuenten con apoyo social. Los lobbies han entendido que la opinión pública puede convertirse además en la forma de llegada más directa a los decisores. De esta manera, puede servir para introducir una cuestión en la agenda política, lograr una reunión que no termina de producirse, fortalecer la legitimidad de sus propuestas, o cambiar los términos de una negociación.

42 En esta línea el lobby también entiende la necesidad de trabajar la sensibilización, el camino más largo pero también el más seguro para lograr incidencia pública promoviendo «un cambio en diferentes planos: en el de los conocimientos, en el de los valores y en el de las actitudes (en el pensar, en el sentir y en el actuar)» (Ingeniería sin Frontera, 2010: 75). Así lo han entendido organizaciones como Médicos del Mundo, que en su página web señala cómo para lograr sus objetivos: «necesitamos sensibilizar a la sociedad». Para este fin, elementos como congresos, seminarios, exposiciones, libros, documentales y campañas de sensibilización, aunque no tengan un objetivo de lobby específico, suponen una tremenda ayuda al fomentar y crear, si tienen éxito, una cultura y unos comportamientos que favorecerán para la defensa de los objetivos perseguidos.

43 Revuelta, A. Villoria, M. «La regulación de los grupos de interés como instrumento de prevención de la corrupción» en «La corrupción en España. Ámbitos, causas y remedios jurídicos» VILlORIA, M. Gimeno, J. M. Y Tejedor, J. Atelier Libros, 2016. Pág. 410

44 Villoria, M. (dir) y Revuelta, A. (coordinadora) (2015), Una evaluación del lobby en España: Análisis y propuestas. Transparencia Internacional España. 
1. Financiación de partidos políticos para obtener regulaciones beneficiosas una vez que los partidos financiados accedan al gobierno;

2. Puertas giratorias;

3. Captura regulatoria y técnica (por ejemplo mediante el control de los grupos de expertos, la financiación de investigación sesgada, o la financiación de congresos y reuniones profesionales a cambio de apoyo difuso a los intereses de los financiadores);

4. Adopción de normas que generan voluntariamente lagunas o loopholes para evitar los verdaderos controles (diluting regulation);

5. Adopción de normas que debilitan las restricciones hasta convertir ciertas leyes en un verdadero ejemplo de fachada o window dressing (debilitating restrictions);

6. Debilitamiento de los controles y la aplicación de las leyes en la fase regulatoria (weakened enforcement).

7. Entorpecimiento de la aplicación de sanciones a través de presiones a los decisores (weakened penalties);

8. Redacción fraudulenta de términos de referencia en un contrato público para asegurar que lo obtenga un sujeto privilegiado, etc.

c) El sujeto pasivo del lobby

Al hablar de modelos regulatorios nos encontramos con otro elemento relevante, el de los sujetos pasivos de la presión, aquellos que reciben son objeto de la influencia en su toma de decisiones. En este sentido es habitual hablar del lobby ante el poder legislativo y el lobby ante el poder ejecutivo, aunque en algunos países se habla también con frecuencia del lobby judicial. Mientras algunos países optan por regular solamente la actuación de los lobbies en un campo, normalmente el legislativo, hay otros que, aunque regulen ambos, lo hacen de forma separada, como ha venido haciendo hasta hace muy poco la Unión Europea y sigue haciendo en Estados Unidos, sólo algunos optan por regularlo de manera conjunta.

En este trabajo, centrado principalmente en España, vamos a analizar las respuestas normativas ante la acción de los grupos de presión que tratan de influir en el poder ejecutivo.

La razón es clara. A estas alturas resulta a todas luces innecesario explicar cómo el núcleo del poder normativo, en nuestro sistema constitucional, está en el Gobierno, canalizado a través de la iniciativa legislativa y la potestad reglamentaria. Así lo vienen corroborando distintos estudios empíricos que coinciden en 
señalar como más del $90 \%$ de las normas que son finalmente aprobadas por el Parlamento tienen su origen en el poder ejecutivo ${ }^{45}$.

Si el constitucionalismo es básicamente control al poder, los controles deberán ponerse en los centros de decisión, y actualmente éstos se encuentran principalmente en el Gobierno y en las relaciones que los lobbies tienen con los distintos responsables de la administración. De ahí la conveniencia de buscar una respuesta jurídica a la actuación que estos grupos desarrollan para influir en el poder ejecutivo, específicamente en la elaboración de leyes o normas con rango de ley (antes de llegar al Parlamento) así como en la elaboración de disposiciones generales y la elaboración y aplicación de las políticas públicas. Pero no podemos olvidar que para realizar esta labor de influencia directa son muchas las actividades más informales, como invitaciones, regalos, o expectativas laborales generadas en cargos públicos, que sin una intención de influencia directa buscan crear posibilidades de acceso, crear un clima de confianza, permanecer en la agenda de los decisores, con expectativas a medio y largo plazo.

\section{LA REGULACIÓN ACTUAL DEL LOBBY EN ESPAÑA}

Aunque estas actividades en nuestro país no están reguladas de manera específica eso no quiere decir que el tema haya estado ausente de nuestro debate normativo.

Ya en el debate constituyente se propuso, dentro de la regulación del derecho de petición ante las Cámaras, la regulación de esta materia, aunque siempre vinculada al ámbito parlamentario ${ }^{46}$. Desde entonces las propuestas de regulación, en ámbito parlamentario o en el del poder ejecutivo, se han ido sucediendo ${ }^{47}$.

45 Jiménez Aparicio, E., «El procedimiento de elaboración de los anteproyectos de ley: la fase gubernamental», en MENÉndez, A. (Dir.) y PAU, A. (Dir. adjunto), La proliferación legislativa: un desafío para el Estado de Derecho, Civitas-Colegio libre de eméritos, Madrid, 2004. Pp. 315 y ss

46 La propuesta planteaba añadir dos apartados más a este punto: se añadían dos párrafos 1: «3. Las Comisiones podrán recibir delegaciones de grupos legítimos de intereses, en sesiones que siempre tendrán carácter público. 4. Una ley orgánica establecerá un sistema de control y registro para los grupos de intereses que actúen de modo permanente». BOCG, núm. 44, de 5 de enero de 1978, pp. 698 y 699.

47 Las primeras se remontan a la IV Legislatura donde podemos localizar la Proposición de Ley relativa al establecimiento por el Congreso de los Diputados de un Registro público de grupos de interés y un Código Deontológico de los mismos (122/000151), Proposición no de Ley relativa al establecimiento por el Congreso de los Diputados de un Registro público de grupos de interés y un Código Deontológico de los mismos. (162/000238), Proposición no de Ley sobre la regulación de los grupos de interés (162/000244). E incluso la Solicitud de creación de una Ponencia en el seno de la Comisión de Reglamento para debatir el establecimiento de un Registro público de grupos de interés y sus normas de funcionamiento (154/000046).

Pasarán los años, hasta la IX Legislatura, para volver a encontrar iniciativas parlamentarias en este sentido, como Proposición no de Ley sobre creación de un registro de lobbies o grupos de intereses (162/000007) de ERC-ICV (2008) y la Proposición no de Ley sobre creación de un registro de lobbies o grupos de intereses. $(161 / 000001)$. 
El debate adquirió más fuerza fue durante la discusión de la Ley 19/2013, de 9 de diciembre, de transparencia, acceso a la información pública y buen gobierno, especialmente después de que el presidente del Gobierno Mariano Rajoy, en el Debate del Estado de la Nación de febrero de 2013 señalara la necesidad de una «regulación parlamentaria de las organizaciones de intereses (los llamados lobbies), con medidas que clarifiquen cuáles pueden ser sus actividades y cuáles deben ser sus límites ${ }^{48}$. En la fase de enmiendas a dicha ley todas las fuerzas políticas salvo el Grupo Parlamentario Popular, plantearon enmiendas en el sentido de regular la actividad de estos grupos ${ }^{49}$.

En los últimos tiempos algunas Comunidades Autónomas han afrontado la regulación del lobby y lo han hecho desde la perspectiva del poder ejecutivo así Aragón se refiere a «cualesquiera de los cargos o autoridades del sector público de Aragón, de las Instituciones y órganos estatutarios, así como de sus empleados $»^{50}$, Castilla y La Mancha a aquellos que pretenden «influir directa o indirectamente en los procesos de elaboración de las políticas o disposiciones normativas, en la aplicación de las mismas o en las tomas de decisiones de la Administración de la Junta de Comunidades de Castilla-La Mancha y de sus organismos y entidades

La siguiente legislatura, la X, sería la más prolífica en propuestas de ese tipo y así encontramos una Proposición no de Ley relativa a la creación de un registro general de intereses o «lobbies» (162/001103), Proposición no de Ley para la creación de un registro de lobbies o grupos de intereses (162/000148) (2012) del Grupo Parlamentario de IU, ICV-EUiA, CHA: La Izquierda Plural, Proposición no de Ley para la creación de un registro de lobbies o grupos de intereses (161/000168), Proposición de reforma del Reglamento del Congreso de los Diputados sobre regulación de la actividad de los grupos de interés o lobbies (410/000011) y la Proposición de reforma del Reglamento del Congreso de los Diputados sobre regulación de la actividad de los grupos de interés o lobbies (410/000010).

También en la XI Legislatura se presentó una Proposición de reforma del Reglamento del Congreso así como una Proposición de reforma del Reglamento del Congreso de los Diputados para la creación del Registro de los Grupos de Interés o Lobbies (410/000001).

48 Debate del Estado de la Nación, Mariano Rajoy, 20.2.2013. Disponible en: http://www.cepc.gob. es/docs/default-source/default-document-library/discurso-integro.pdf?sfvrsn=0 (consultado: 3 de noviembre de 2017)

49 El Grupo Mixto solicitaba «Un registro de representantes de grupos de interés....y que estos elaboraran informes periódicos de sus actividades y financiación asi como de sus interlocutores públicos y sus contribuciones de campaña no dinerarias y pagos en eventos a entidades (30).

La propuesta de ERC consistía en solicitar al Gobierno español la presentación ante el Congreso de los Diputados, un Proyecto de Ley de Regulación de los grupos de interés o lobbies. ... En esta regulación se establecerá la creación de un registro de lobbies, la regulación de un código de conducta con fuerza legal, las medidas de transparencia, publicidad y control que deben regirlos, así como las oportunas sanciones en caso de incumplimiento (77 y 178).

Izquierda Plural solicitaba un Proyecto de Ley de Regulación de los grupos de interés o lobbies, que entre otras cuestiones regule la creación de un registro de lobbies, la regulación de mecanismos de control y transparencia de su actividad, así como la descripción de infracciones y su correspondiente régimen sanciona$\operatorname{dor}(259)$.

UPYD hablaba Registros en cada administración y Código de Conducta (362).

CiU planteaba un Registro General de Intereses, siguiendo la normativa europea al respecto. El Registro de Grupos de Interés dependerá de la Agencia Estatal de Transparencia, Evaluación de Políticas Públicas y la Calidad de los Servicios. Y Código de Conducta (438).

50 Ley 5/2017, de Integridad y Ética Públicas de Aragón, art. 35 
públicas vinculados o dependientes» ${ }^{51}$, Cataluña incluye "todas las actividades realizadas con la finalidad de influir directa o indirectamente en los procesos de elaboración o aplicación de las políticas y la toma de decisiones, con independencia del canal o medio utilizado, incluyendo los contactos con autoridades y cargos públicos, diputados, funcionarios y personal al servicio de las instituciones... $\gg^{52}$ o en la Comunidad Autónoma Valenciana, cuyo Anteproyecto de ley habla de «Los cargos públicos y el personal empleado público de la Administración de la Generalitat y de su sector público instrumental, cualquiera que sea su régimen jurídico» ${ }^{53}$.

Más allá de la normativa específica, o la ausencia de ésta, en el ámbito nacional habría que acudir a aquellas las restricciones que afectan a la conducta de los empleados públicos y que se encuentran en el $\mathrm{CP}$, en las normas de función pública, con sus respectivas normas de régimen disciplinario, en las reglas sobre abstención de las leyes reguladoras del procedimiento administrativo y las normas de incompatibilidades.

Las primeras se refieren a los delitos cometidos por la adopción fraudulenta de decisiones públicas, e incluiría los delitos de prevaricación, abuso de funciones, cohecho, o tráfico de influencias, que podrían llevarse a cabo cuando al favorecer determinadas posturas, tras recibir dadivas o regalos de la organización favorecida en un procedimiento administrativo.

Las normas relativas al conflicto de interés, que se centran en un régimen de incompatibilidades que se extiende hasta dos años después del cese, la transparencia sobre causas de posible incompatibilidades y sobre cualquier actividad que les pudiera proporcionar ingresos, así como de sus declaraciones de bienes patrimoniales y la obligación de abstención e inhibición en casos que afecten a sus intereses personales, cubren sólo una parte de las acciones de lobby, aquellas que se realizaran afectaran a los intereses personales, económicos o profesionales, del funcionario público, entendiendo como tal sus intereses propios, los familiares, incluyendo los de su cónyuge o persona con quien conviva en análoga relación de afectividad y parientes dentro del cuarto grado de consanguinidad o segundo grado de afinidad, los de las personas con quien tengan amistad íntima, los de aquellas de personas jurídicas o entidades privadas a las que haya estado vinculado por una relación laboral o profesional de cualquier tipo en los dos años anteriores al nombramiento y los de personas jurídicas o entidades privadas a las que los familiares previstos en la letra b) estén vinculados por una relación laboral o profesional de cualquier tipo, en el ejercicio de funciones de dirección, asesoramiento o administración. Estas medidas, que en ocasiones son criticadas por

51 Ley 4/2016, de 15 de diciembre, de Transparencia y Buen Gobierno de Castilla-La Mancha. art. 43

52 Ley 19/2014, de 29 de diciembre, de transparencia, acceso a la información pública y buen gobierno de Cataluña, Art. 47.2

53 Anteproyecto de Ley, de la Generalitat, reguladora de la actividad de lobby en el ámbito de la Generalitat y de su sector público instrumental, Art. 2 
excesivas, se desenvuelven en el marco de prevenir situaciones de riesgo que puedan derivar en situaciones concretas de corrupción.

En este sentido el ordenamiento establece una regulación preventiva que busca evitar el conflicto de intereses, evitando que la relación profesional previa de una organización con el empleado público, por haber trabajado previamente en la empresa privada, pueda contaminar sus decisiones.

Las incompatibilidades se recogen actualmente en la Ley 3/2015, de 30 de marzo, reguladora del ejercicio del alto cargo de la Administración General del Estado establece un marco amplio de limitaciones en esta materia, y cuya exigibilidad se inicia incluso desde una etapa anterior al nombramiento del alto cargo (pues se le exige que acredite su idoneidad para el puesto) y que se extienden hasta los dos años siguientes al cese.

Además, todas las autoridades y el personal al servicio de las Administraciones Públicas, deberán, según el artículo 23.2.e) de la Ley 40/2015, de 1 de octubre, de Régimen Jurídico del Sector Público, abstenerse en caso de: «Tener relación de servicio con persona natural o jurídica interesada directamente en el asunto, o haberle prestado en los dos últimos años servicios profesionales de cualquier tipo y en cualquier circunstancia o lugar. Este deber de abstención se agrava para los miembros del Gobierno y altos cargos de la Administración General del Estado, a los que el artículo 12 de la LAACC, impone un deber de abstención más riguroso en cuanto que exige obligaciones formales adicionales para su constancia y publicidad.

También es importante considerar en este punto la Ley 7/2007, de 12 de Abril, del Estatuto básico del empleado público en cuyo capítulo VI se establece el Código de Conducta de los empleados públicos que incluye en sus artículos 53 y 54 .

\section{OTRAS RESPUESTAS NORMATIVAS A LA INFLUENCIA: TRANSPARENCIA, CÓDIGOS DE CONDUCTA Y FORMAS DE PARTICIPACIÓN.}

Como hemos señalado anteriormente nosotros proponemos abordar la transparencia de los grupos de presión desde la transparencia de sus actuaciones, aunque esta solución tampoco esté exenta de problemas, pues nos enfrentamos, como hemos visto, a un abanico enorme de actividades entre las que un buen número de ellas serían actividades informales sin un objeto de influencia específico, sino con objetivos de influencia indirectos, como los que están detrás de la mayoría de las señaladas anteriormente.

Además consideramos que una regulación de las actuaciones de los grupos de presión tiene que ir mucho más allá del establecimiento de medidas de transparencia como las vistas, de ahí que propongamos otra serie de medidas destinadas a facilitar la participación de estos grupos en política. Este tipo de medidas 
contribuirán a, como estamos proponiendo, ir más allá del control y buscar una auténtica democratización de las actuaciones de los grupos.

Coincidimos con Transparencia Internacional cuando señala que «(L)a regulación del proceso de elaboración de leyes y de reglamentos debería revisarse, para asegurar un campo de juego equilibrado entre los intereses en juego... se precisa mayor garantía de participación para todos los afectados, más información acerca de los mecanismo de consulta y participación y canales claros de comunicación entre ciudadanos y gobiernos/parlamentos ${ }^{54}$.

\section{a) Transparencia}

\section{El registro y los informes periódicos}

Como ya hemos visto, desde la Federal Regulation of lobbying Act de 1946 (USA) el modelo de control de los grupos de presión ha girado en torno a la creación de un registro que permita identificar a todas aquellas personas físicas o jurídicas que pueden establecer relaciones con las instituciones públicas, así como conocer sus intereses, sus clientes, las actividades realizadas con este fin y los recursos empleados en ellas. Se trata de un modelo tradicional de transparencia centrada en el sujeto.

$\mathrm{Al}$ establecer este tipo de registros para las organizaciones se plantean varios interrogantes, tales como la voluntariedad u obligatoriedad, y los incentivos y penalizaciones de los que opten por no registrarse, que pueden ser, entre otros, el acceso a los poderes públicos por parte de los inscritos; información sobre iniciativas y proyectos relacionada con sus ámbitos declarados de interés o acceso a reuniones o conferencias informativas que puedan organizarse por parte del gobierno.

El segundo interrogante trata sobre el establecimiento de un registro común para todas las administraciones y organismos públicos o la creación de uno para cada administración y el tercero sobre la extensión de los datos que los registros deben ofrecer.

Este modelo de registro suele venir acompañado habitualmente de la obligación de presentar informes periódicos centrados fundamentalmente en la actividad. En este sentido, hay que detallar los procedimientos en los que se ha participado, quién ha participado en los mismos, los responsables públicos con los que se ha tenido relación durante el periodo, el presupuesto dedicado a esta actividad o el dinero facturado en compensación de los servicios prestados, si se ha trabajado para terceros. Otros van más allá al incluir en estos informes la publicidad de «las actuaciones de los grupos de interés, especialmente de las

54 «Una evaluación del lobby en España: Análisis y propuestas», Transparencia Internacional, 2014. Pág. 103 
reuniones y audiencias celebradas con autoridades, cargos públicos, miembros electos o diputados, y de las comunicaciones, los informes y otras contribuciones con relación a las materias tratadas ${ }^{55}$

Lo que resulta interesante desde nuestra perspectiva, es que es necesario ofrecer el detalle de las actuaciones de influencia de cualquier tipo, sobre las que han pretendido ejercer acciones de influencia. El modelo del registro que nosotros planteamos sería muy similar al contemplado anteriormente con la única diferencia de que, según nuestra propuesta, el registro se basaría no en la naturaleza de los grupos, sino en las actividades desarrolladas, de las que ya es necesario dar cuenta en los informes periódicos. De esta manera, se resolverían los interrogantes planteados no existiendo la necesidad de plantear la obligatoriedad del registro, ya que todas las actividades se incorporarían automáticamente al mismo. Tampoco existiría la necesidad de optar entre uno o más registros, al construirse en la página web un único registro, fruto de la acumulación organizada de las actividades realizadas. Por último, la extensión de los datos se ampliaría al recoger la actividad desarrollada y no tanto por los detalles de la organización, aunque de manera natural incorporaría la mayoría de la información que hoy se requiere en un registro de lobbies. Además, como se puede ver, el código de conducta se centra en la actividad individual, por lo que, según nuestra propuesta, conservaría su eficacia.

En nuestro país actualmente sólo existe un registro de lobby nacional ${ }^{56}$, el de la CNMC. Se trata de un registro voluntario, que adopta una definición amplia de grupos de interés, que incluye a aquellos que actúan en defensa de intereses propios, de terceros o incluso de otros intereses generales. De esta manera su ámbito objetivo agrupa empresas y grupos de empresas, organizaciones no gubernamentales o corporaciones de derecho público, entre otros. Este Registro es de carácter público y gratuito, y, su gestión y tramitación plenamente electrónica y el alta en el mismo conlleva un compromiso, recogido en unos Principios de Actuación de obligado cumplimiento (que veremos con más detalle al hablar de los códigos de conducta).

\section{La agenda de los cargos públicos}

Para tener acceso a estas actividades de influencia sobre las que pretendemos centrar el registro, no hay forma más segura que hacerlo a través de la agenda pública de los cargos públicos. Esto, además de para conocer más a fondo su trabajo nos puede permitir conocer a los actores que están participando activamente

55 Ley 19/2014, de 29 de diciembre, de transparencia, acceso a la información pública y buen gobierno, Art. 49.

56 Hoy están operativos también los registros establecidos por la Ley 19/2014, de 29 de diciembre, de transparencia, acceso a la información pública y buen gobierno. 
en las decisiones públicas haciendo llegar sus puntos de vista y propuestas a la administración fuera de los trámites formales establecidos.

En este sentido, los partidarios de la publicidad de las agendas públicas, plantean la necesidad de hacer públicos los informes periódicos de entrevistas de miembros del Gobierno con diferentes grupos de presión, así como del contenido de las mismas, incorporando tanto el resumen de lo tratado como los dictámenes que se hayan realizado como consecuencia de las mismas.

De este modo, podemos decir que la publicidad de las agendas está relacionada, aunque no exclusivamente, con la regulación de la actividad de los grupos de interés. La agenda dará publicidad a las actividades de naturaleza pública que lleven a cabo y se incluirá en la página de Internet de sus respectivas instituciones. Para garantizar la eficacia de la misma, sería conveniente definir un estándar de publicación con formato abierto y reutilizable que, además de permitir su actualización de forma consistente y ágil, establezca plazos para la publicación y permita procesar de manera conjunta la información.

Según este modelo, la agenda se convertiría, de manera indirecta, en complemento o base del registro de grupos de interés, al visibilizar a todas aquellas personas o entidades que realizan actividades dirigidas a influir de manera directa sobre los diputados. La agenda se convierte así en un pseudoregistro concentrado en aquellos que hacen lobby y no solamente en los que se identifican como tales, resolviendo, como hemos visto, el problema de la voluntariedad.

En España no existe obligación de hacer públicas estas agendas de manera activa, y así lo ha dejado claro el Consejo de Transparencia, pero se ha planteado con frecuencia la obligación de proporcionar esa información a través del derecho de acceso a la información pública. Estas reiteradas solicitudes han dado lugar a un criterio interpretativo conjunto del Consejo de Transparencia y Buen Gobierno y la Agencia Española de Protección de Datos, CI 002/20016, en el que se determina que solo es posible solicitar información relativa a reuniones celebradas en el ejercicio de funciones públicas y en condición de responsable público. Que la información deberá ser proporcional a la importancia del interés público existente en la divulgación de la información y que, cuando se solicite información identificativa de los participantes se protegerán aquellos datos personales especialmente protegidos, y se facilitarán aquellos que afecten a miembros del Gobierno, Altos Cargos, directivos públicos profesionales, empleados públicos o personal de sujetos obligados por le ley de transparencia. Que en el caso de participantes de entidades de derecho privado, la información identificativa se limitará a administradores o miembros de sus órganos de gobierno o dirección, o altos directivos y que cuando en la reunión hubieran participado asesores o consultores, lugar que habitualmente ocupan los grupos de presión, la información se limitaría a señalar esta circunstancia sin incluir otra información identificativa de los mismos. Mientras que el resto de participantes no deben ser identificados, basta con mencionar el órgano, o la entidad privada a la que pertenecen. En todos 
los casos anteriores los asistentes podrían prestar su consentimiento, según las exigencias de la LOPD.

\section{La buella normativa}

La ley 19/2013 señala en su preámbulo que «solo cuando la acción de los responsables públicos se someta a escrutinio, cuando los ciudadanos pueden conocer cómo se toman las decisiones que les afectan,... o bajo qué criterios actúan nuestras instituciones podemos hablar del inicio de un proceso en que los poderes públicos comienzan a responder...»

Así lo muestra, con ejemplos concretos, Transparencia Internacional que, en su informe sobre el estado del lobby en España, denuncia como habitualmente en estas negociaciones, que tienen lugar de forma informal, suelen participar todos los actores implicados o interesados en esta política, señalando también como «de todas estas reuniones no hay información pública: el proceso de generación de las modificaciones no ha sido público, ni se ha seguido un proceso de consultas y participación democrático» ${ }^{57}$.

De ahí la relevancia de poder conocer las modificaciones que se han ido introduciendo en un texto normativo durante su trámite parlamentario, algo que hoy es posible, y la necesidad de ir más allá de los debates parlamentarios, para entender las causas, motivaciones y actores que han influido en todo el proceso, especialmente en la fase inicial del mismo.

La tecnología existente permitiría que aquellos que estén interesados pudieran conocer el iter de cualquier decisión pública desde el principio de su elaboración, así como los distintos cambios que a propuesta de afectados, interesados y expertos se han ido introduciendo, con el fin de dotar de mayor transparencia a todo el proceso y permitir a los ciudadanos saber cómo ha evolucionado una norma y en qué sentido.

De este modo, se podría dotar a todos los actos normativos tramitados por el poder Ejecutivo y el Legislativo de una memoria de análisis de trazabilidad o huella digital. Esta huella incorporaría no sólo una relación de los actores que han intervenido, sino el momento en el que lo han hecho y la información proporcionada por cualquier vía durante el proceso. Información pública, según el artículo 13 de la ley, abarca «los contenidos o documentos, cualquiera que sea su formato o soporte, que obren en poder de algunos de los sujetos incluidos en el ámbito de aplicación de a Ley y que hayan sido elaborados o adquiridos en el ejercicio de sus funciones». Algo que como el Consejo deja claro, busca que se proporcione toda aquella «información que tenga relevancia en la tramitación del expediente o en

57 «Una evaluación del lobby en España: Análisis y propuestas», Transparencia Internacional, 2014. 
la conformación de la voluntad pública del órgano,... relevante para la rendición de cuentas, el conocimiento de la toma de decisiones públicas y su aplicación» ${ }^{58}$.

De esta manera, aunque cabe la posibilidad de solicitar esta información pública de manera proactiva, el hecho de que ésta esté disponible en las páginas web junto al resto de información relativa a cada iniciativa legislativa y en formatos reutilizables, supondría una garantía de transparencia de la actuación de estos grupos de presión.

El conocimiento público de las propuestas presentadas por los grupos de interés favorecerá la transparencia del procedimiento sin que haya sospechas de la existencia de zonas oscuras o que escapan al normal funcionamiento de los mecanismos de representación. Además, si la actualización se realizara a tiempo, esta información proporcionada estaría también a disposición del resto de decisores mejorando las posibilidades de deliberación, negociación y, en último término, la calidad democrática del proceso ${ }^{59}$.

\section{La transparencia en la relación con los medios de comunicación y la movilización social}

Como consecuencia del papel que juega la opinión pública en la toma de decisiones pública, del que hemos hablado antes, existe otra vía de transparencia utilizada en ocasiones al buscar respuesta a las actuaciones del lobby. Se trata de la obligación de dar cuenta del nombre de aquellas publicaciones en las que la campaña hubiera publicado artículos o editoriales con intención de presionar (FRLA, 1946).

También algunos países como Canadá establecen la obligación de registrarse en el Registro de lobby para aquellos que realizan actividades de «grass-roots lobbying», aquellas que utilizan técnicas de movilización social para influir en los poderes públicos, tanto en el diseño estratégico como en la organización de este tipo de actividades.

$58 \mathrm{CI} / 006 / 2015$, de 12 de noviembre

59 La normativa española plantea una dificultad en este sentido al establecer en el artículo 18.1.b) de la ley 19/2013, que la «información que tenga carácter auxiliar o de apoyo como la contenida en notas, borradores, opiniones, resúmenes, comunicaciones e informes internos o entre órganos o entidades administrativas» podrá no ser entregada en caso de solicitud de acceso a la información pública. Desde entonces esta excepción ha sido utilizada con frecuencia por la administración lo que ha requerido una intervención del Consejo de la Transparencia que en su criterio interpretativo CI/006/2015, de 12 de noviembre, ha señalado que la obligada justificación de la inadmisión de la solicitud de esta información debe motivar la «condición principal de auxiliar o apoyo» de la información denegada, y no basta para ello alegar su condición de nota, borrador, opinión, resumen o informe interno... Esto dejaría fuera a aquellos documentos que a) contienen opiniones o valoraciones del autor y no manifiesten la posición de un órgano o entidad, B8 cuando se trate de un texto preliminar o borrador, c) o información preparatoria de la actividad, d) se refiera a comunicaciones internas que no constituyan trámites de procedimiento y, por último, e) los informes no preceptivos que no hayan sido incorporados como motivación de la decisión final. 
El diseño estratégico incluiría actividades como la aprobación de elementos, el asesoramiento a estas campañas, la contribución con estudios y análisis, el diseño de mensajes o la preparación de contenidos y material para este tipo de campañas de alto componente social. Mientras que las actividades de organización incluirían la distribución de estos contenidos (tanto en papel como en la red), la interacción con la sociedad en nombre de la campaña (respondiendo llamadas o cartas, realizando presentaciones, o asumiendo funciones de portavocía) así como en la gestión del día a día de estas campañas.

\section{b) Códigos de conducta}

\section{Los Códigos de conducta de los que desarrollan actividades de influencia}

Además de fomentar la participación una regulación que pretenda abordar el problema del lobby debería también controlar con otros mecanismos distintos a la transparencia el comportamiento de aquellos que quieren ejercer presión y los decisores. En esta línea algunos ordenamientos establecen códigos de conducta, que se convierte en condición para la inscripción y la permanencia en el registro y que incluye una serie de normas que todos deberían respetar en sus relaciones de influencia con los distintos poderes públicos. Estos consisten básicamente en Identificarse, de manera personal o de la organización en nombre de la que se presenta, así como los intereses que defiende. No falsear la información y los datos aportados al registro. Velar por aportar información neutra, completa, actualizada y no engañosa. Respetar la legislación aplicable a las incompatibilidades de los cargos públicos, evitar los conflictos de intereses y evitando siempre proponer una contraprestación al responsable público a cambio de sus servicios. ${ }^{60}$

Como señalábamos anteriormente en España ha sido la $\mathrm{CNMC}^{61}$ el primer organismo público en establecer un Código de Conducta de obligado cumplimiento para aquellos que forman parte de su registro. Este decálogo añade a los principios genéricos ya reseñados, el respeto a las instituciones y personas con quienes se relacionan, la transparencia de informar explícitamente de que actúan como grupo de interés y están inscritos en el Registro, el no difundir información de carácter confidencial que hubieran conocido en el ejercicio de su actividad y aceptar que parte de la información que ellos han proporcionado se haga pública.

Actuar con integridad y honestidad en el desarrollo de su actividad y no influir ni intentar influir en la toma de decisiones de manera deshonesta ni obtener o intentar obtener información de manera, no realizar ningún obsequio de

60 Por todos el Code of Conduct in Annex 3 of the 2014 Interinstitutional Agreement on the Transparency Register, de la Unión Europea.

61 En el caso de la CNMC se denomina Decálogo ético. Disponible en: https://rgi.cnmc.es/decalogo-etico (consultado el 3 de noviembre de 2017). 
valor ni ofrecer ningún favor o servicio que pueda comprometer la ejecución íntegra de las funciones públicas.

A esto se añaden dos elementos novedosos, vinculados al propio registro al obligarse a informar a las personas u organizaciones a quienes representen de la existencia de los presentes Principios de Actuación y al mismo tiempo a no hacer uso abusivo del alta para darse publicidad, ni dar a entender que les confiere una situación o privilegio especial ante los poderes públicos.

En otras ocasiones son las propias asociaciones del sector las que establecen estos Códigos de Conducta como condición previa para poder formar parte de la asociación. En España este es el modelo adoptado por APRI ${ }^{62}$.

\section{Los Códigos de conducta para cargos públicos}

Por el otro lado existen también códigos éticos y de conducta que establecen el comportamiento más apropiado del cargo público ${ }^{63}$. Estos documentos definen los principios y reglas de comportamiento éticos que una organización entiende $\mathrm{y}$ asume que deben aplicarse a las actividades que desarrolla, tanto en sus relaciones internas como en sus relaciones externas, así como a sus actuaciones y a sus pautas de gobernanza. Estos Códigos, que tratan de dar respuesta a eventuales conflictos de intereses, establecen la obligación de presentar una declaración de bienes y/o de intereses, suelen incluir las obligaciones que puede contraer el Alto Cargo frente a entidades a las que presta servicios, estableciendo un elenco de incompatibilidades y prohibiciones e incluyen también materias como el uso de información confidencial o el uso indebido de las instalaciones y el personal.

En España, junto a la existencia de códigos de conducta en las Comunidades Autónomas ${ }^{64}$, estos códigos forman parte de la Ley del Estatuto Básico del Empleado Público que, en lo que podría afectar al lobby, establece entre sus principios éticos el respeto a la Constitución y a las normas (1), la satisfacción de los intereses generales de los ciudadanos y se fundamentará en consideraciones objetivas orientadas hacia la imparcialidad y el interés común, al margen de cualquier otro factor que exprese posiciones personales, familiares, corporativas, clientelares

62 Disponible en: http://relacionesinstitucionales.es/apri-asociacion-de-profesionales-de-relaciones-institucionales/codigo-de-conducta/ (consultado el 3 de noviembre de 2017).

63 El ejemplo más paradigmático de estos Códigos de Conducta es el Código de Conducta del personal de la UE. Disponible en: https://ec.europa.eu/info/sites/info/files/code-of-good-administrative-behaviour_ en.pdf (consultado el 3 de noviembre de 2017).

64 Por todos: País Vasco: Ley 1/2014, de 26 de junio, Reguladora del Código de Conducta y de los Conflictos de Intereses de los Cargos Públicos; Decreto 156/2016, de 15 de noviembre, sobre obligaciones y derechos del personal cargo público. Cataluña: Acuerdo GOV/82/2016, de 21 de junio. LCAT 2016 325. Aprueba el Código de conducta de los altos cargos y personal directivo de la Administración de la Generalidad y de las entidades de su sector público, y otras medidas en materia de transparencia, grupos de interés y ética pública. 
o cualesquiera otras que puedan colisionar con este principio (2), absteniéndose en aquellos asuntos en los que tengan un interés personal, así como de toda actividad privada o interés que pueda suponer un riesgo de plantear conflictos de intereses con su puesto público, (5) vigilarán la consecución del interés general y el cumplimiento de los objetivos de la organización(8), no influirán en la agilización o resolución de trámite o procedimiento administrativo sin justa causa y, en ningún caso, cuando ello comporte un privilegio en beneficio de los titulares de los cargos públicos o su entorno familiar y social inmediato o cuando suponga un menoscabo de los intereses de terceros, (9) ejercerán sus atribuciones absteniéndose de conductas que comprometan la neutralidad en el ejercicio de los servicios públicos, (11) y guardarán secreto de las materias clasificadas u otras cuya difusión esté prohibida legalmente, y mantendrán la debida discreción sobre aquellos asuntos que conozcan por razón de su cargo, sin que puedan hacer uso de la información obtenida para beneficio propio o de terceros, o en perjuicio del interés público(12). ${ }^{65}$

Se establecen también una serie de principios de conducta, que en lo que afecta a la actuación de los lobbies supondría administrar los recursos y bienes públicos con austeridad, y no utilizar los mismos en provecho propio o de personas allegadas $(5)^{66}$.

\section{Regalos y expectativas}

Dentro de estos códigos de conducta, hemos querido analizar a parte una serie de normas que afectan especialmente a las actuaciones de los grupos de presión. Se trata de aquellas que procuran evitar que los grupos de presión logren provocar en el funcionario público una decisión contraria al interés general, a través del ofrecimiento de beneficios personales o familiares, de naturaleza económica o empresarial, o expectativas de los mismos, a través de dádivas, beneficios, privilegios, invitaciones, etc. o la expectativa de estos, especialmente en forma de empleo.

Este puede ser material (tangible) o inmaterial (por ejemplo, invitación a actos culturales, atenciones especiales, etc.) y la normativa adopta una posición según la cual hay que suponer que su objetivo será siempre lograr un contacto, o una acogida favorable para futuras decisiones. Para dar respuesta jurídica a este comportamiento el Código Penal establece el delito de cohecho ${ }^{67}$.

En esta línea la Ley del Estatuto Básico del Empleado Público, a la que ya nos hemos referido, señala que los funcionarios públicos «(N)o aceptarán ningún

65 Real Decreto Legislativo 5/2015, de 30 de octubre, por el que se aprueba el texto refundido de la Ley del Estatuto Básico del Empleado Público. Art. 53

66 Real Decreto Legislativo 5/2015, de 30 de octubre, por el que se aprueba el texto refundido de la Ley del Estatuto Básico del Empleado Público. Art. 54

67 Título XIX del Código Penal, Delitos contra la Administración Pública (419-424). 
trato de favor o situación que implique privilegio o ventaja injustificada, por parte de personas físicas o entidades privadas» ${ }^{68}$, y más adelante «se rechazará cualquier regalo, favor o servicio en condiciones ventajosas que vaya más allá de los usos habituales, sociales y de cortesía, sin perjuicio de lo establecido en el Código Penal» ${ }^{69}$.

También lo hace la Ley de transparencia, cuando en su Título II, referido al buen gobierno impone como principio de actuación el que los miembros del Gobierno y altos cargos de la Administración General del Estado: «No aceptarán para sí regalos que superen los usos habituales, sociales o de cortesía, ni favores o servicios en condiciones ventajosas que puedan condicionar el desarrollo de sus funciones. En el caso de obsequios de una mayor relevancia institucional se procederá a su incorporación al patrimonio de la Administración Pública correspondiente, (6) ni se valdrán de su posición en la Administración para obtener ventajas personales o materiales. $(9)^{70}$ »

Así aunque del tenor literal de estos artículos se podría deducir la prohibición absoluta de recibir regalos, la realidad es que, aunque hay una censura clara ante los regalos cuando implican alguna actuación activa por parte del funcionario, en cambio, en algunos sectores se considera normal la aceptación de pequeños obsequios, invitaciones a comidas, etc., cuando, aparentemente, no se está directamente implicado en la toma de decisiones. Esta práctica habitual de aceptar determinados presentes de escaso valor o invitaciones, por ejemplo a comer, hace que la regulación vaya más allá, admitiendo que los empleados públicos aceptan determinados regalos, y estableciendo cautelas adicionales y mecanismos de control.

\section{c) Participación}

\section{Consejos Consultivos}

Existen otras vías, más indirectas, que pueden también contribuir a mejorar la transparencia de las actuaciones de los grupos de interés. Se tratar de las normas que regulan la participación de la sociedad civil en la toma de decisiones. Desde los años noventa, se ha asentado en España un modelo asimétrico de institucionalización de la actividad de muchos grupos de interés que varía enormemente en función de las actividades a las que se dedican, pero que ha hecho proliferar formas institucionales de interacción e influencia cotidiana con los decisores públicos. Todas estas normas procuran a los grupos un acceso especial a

68 Ley 7/2007, de 12 de abril, del Estatuto básico del empleado público. Art. 53.7.

69 Ley 7/2007, de 12 de abril, del Estatuto básico del empleado público. Art. 54.6.

70 Ley 19/2013, de 9 de diciembre, de transparencia, acceso a la información pública y buen gobierno, Título II, artículo 26.2.b). 
ciertos comités, consejos, grupos de expertos o foros que influyen en las regulaciones sectoriales, foros a los que también tienen acceso por distintas vías los grupos de interés.

Este modelo de participación institucional, inspirado en las teorías de democracia deliberativa Habermasiana, se apoya en este tipo de órganos colegiados como mecanismo para canalizar los distintos intereses y facilitar la interacción de distintos actores.

Como recoge Cerrillo, la figura del órgano colegiado, puede constituir un buen mecanismo a través del cual hacer frente a la institucionalización a la que se refiere Habermas al afirmar que «el desarrollo y la consolidación de una política deliberativa, la teoría del discurso los hace depender, no de una ciudadanía colectivamente capaz de acción, sino de la institucionalización de los correspondientes procedimientos y presupuestos comunicativos, así como de la interacción de deliberaciones institucionalizadas con opiniones públicas desarrolladas informalmente» ${ }^{71}$.

En España estos consejos consultivos se regulan dentro de los órganos colegiados definidos como aquellos creados formalmente e integrados por tres o más personas, «a los que se atribuyan funciones administrativas de decisión, propuesta, asesoramiento o control, y que actúen integrados en la Administración General del Estado o alguno de sus Organismos públicos $»^{72}$. El problema reside en que a pesar de la normativa básica aplicable ${ }^{73}$, el artículo 15.2 matiza que «(L) os órganos colegiados de las distintas Administraciones Públicas en que participen organizaciones representativas de intereses sociales... podrán establecer $\mathrm{o}$ completar sus propias normas de funcionamiento» ${ }^{74}$.

De esta forma hoy en día existen en España más de 90 consejos de este tipo, permanentes o ad hoc, vinculados a la AGE que cuentan con estructura, composición, funcionamiento y funciones diversas y poco claras que en la práctica se muestran incapaces de responder al objetivo de hacer llegar los intereses sociales a las administraciones públicas y evitar los riesgos que podría causar una posición privilegiada de los grupos de presión.

\section{Procedimientos de consulta pública previa y de audiencia e información pública}

Otro de los mecanismos de institucionalización de la participación ciudadana serían las consultas públicas previas y de audiencia e información pública. Como señala el informe Mandelkern sobre mejora de la regulación, asumido por

71 Cerrillo, A. «La participación en los órganos colegiados en la administración en red» en Revista Vasca de Administración Pública, núm. 90. Mayo-Agosto 2011. Pág. 87.

72 Art. 20 Ley 40/2015, de 1 de octubre, de Régimen Jurídico del Sector Público.

73 Título I, Sección 3 (art. 15-22) Ley 40/2015, de 1 de octubre, de Régimen Jurídico del Sector Público.

74 Art. 15.2 Ley 40/2015, de 1 de octubre, de Régimen Jurídico del Sector Público. 
las instituciones de la Unión Europea, la participación y la consulta con los ciudadanos es el primer requisito del principio de transparencia ${ }^{75}$. De esta manera los procesos de consulta no deberían ser considerados únicamente como formas de protesta sino como un instrumento para dar forma a la regulación o las políticas públicas $^{76}$.

Pero, como ya hemos advertido, este papel necesario de la participación en los procesos de políticas públicas tiene también el peligro de que los mismos queden en manos de los "profesionales de la participación» y que sólo aquellos con recursos de tiempo, personal o dinero suficientes, puedan tener acceso a estos procesos de negociación, ejerciendo una influencia debida e incluso supuestos de corrupción. De ahí nuestra insistencia en regular los canales de participación política con esta mentalidad de acabar con la opacidad de las negociaciones informales y equilibrar el terreno de juego de la participación. De hecho algunas normas, como la ley catalana, consideran ya como acción de lobby la participación en estos procesos y así definen acción de lobby como «las contribuciones y la participación voluntarias en consultas oficiales sobre propuestas legislativas, normativas, actos jurídicos u otras consultas» ${ }^{77}$.

Dentro de este objetivo de introducir procedimientos que permitan al público comunicar sus preocupaciones a sus representantes sobre procedimientos abiertos, para que puedan influir realmente en la toma de decisiones sobre los mismos, el ordenamiento español establece los trámites de consulta pública previa y de audiencia e información pública en el proceso de elaboración de los anteproyectos de ley, proyectos de real decreto legislativo y proyectos de normas reglamentarias ${ }^{78}$.

Los trámites de consulta pública previa tienen como objetivo mejorar la participación de los ciudadanos en el procedimiento de elaboración de normas, con carácter previo a la elaboración del texto normativo, por lo que busca recabar la opinión de los sujetos y las organizaciones más representativos potencialmente afectados por la futura norma acerca de: a) los problemas que se pretenden solucionar con la iniciativa, b) la necesidad y oportunidad de su aprobación, c) los objetivos de la norma y d) las posibles soluciones alternativas regulatorias y no regulatorias.

Por el contrario los trámites de audiencia e información pública tienen por objeto recabar la opinión de los ciudadanos titulares de derechos e intereses

75 Informe del grupo Mandelkern sobre mejora de la regulación (2011). Disponible en: http://ec.europa.eu/smart-regulation/better_regulation/documents/mandelkern_report.pdf (consultado el 3 de noviembre de 2017). Pág. 10

76 Informe del grupo Mandelkern sobre mejora de la regulación (2011). Disponible en: http://ec.europa.eu/smart-regulation/better_regulation/documents/mandelkern_report.pdf (consultado el 3 de noviembre de 2017). Pág. 27

77 Ley 19/2014, de 29 de diciembre, de transparencia, acceso a la información pública y buen gobierno, art. 47.2

78 Art. 133 de la Ley 39/2015, de 1 de octubre, del Procedimiento Administrativo Común de las Administraciones Públicas, y art. 26 de la Ley 50/1997, de 27 de noviembre, del Gobierno. 
legítimos afectados por un proyecto normativo ya redactado, directamente o a través de las organizaciones o asociaciones que los representen, así como obtener cuantas aportaciones adicionales puedan realizar otras personas o entidades ${ }^{79}$. En el caso del trámite de información pública resulta potestativo, por lo que el órgano resolutorio puede acordar o no su apertura, en función de la naturaleza del procedimiento $^{80}$.

No es la única posibilidad de participación de los ciudadanos puesto que las Administraciones Públicas podrán establecer otras formas, medios y cauces de participación de las personas, directamente o a través de las organizaciones y asociaciones reconocidas por la ley en el procedimiento en el que se dictan los actos administrativos ${ }^{81}$.

En este sentido la web se presenta como la plataforma preferente para facilitar estos instrumentos que son participativos, en cuanto que son condición sine qua non para el ejercicio de la participación. Esto implica que el Portal de Transparencia ofrezca información actualizada de todas las iniciativas normativa, el estado de tramitación y los procesos de participación abiertos, así como la forma y condiciones para ejercer la participación en los mismos.

El citado informe Mandelkern, señala como es mejor consultar a demasiados que a pocos: «Es de suma importancia que la consulta, dejando aparte casos excepcionables y específicos (por ejemplo, cuestiones de seguridad nacional), no se limite a un grupo específico. Depende del sector consultor el decidir qué personas deberían ser consultadas, aunque, por lo general, es necesario dirigirse a una gama amplia de actores (no solamente los «sospechosos habituales»). La consulta basada en Internet es un medio de garantizar la difusión de información al mayor número posible de interesados». ${ }^{82}$

Para convertir este mecanismo en otra vía de participación abierta verdaderamente a todo tipo de intereses se deberían modificar una serie de elementos estableciendo un procedimiento de audiencias a particulares y entidades cívicas,

79 Tal y como establece la Orden PRE/1590/2016, de 3 de octubre, por la que se publica el Acuerdo del Consejo de Ministros de 30 de septiembre de 2016, por el que se dictan instrucciones para habilitar la participación pública en el proceso de elaboración normativa a través de los portales web de los departamentos ministeriales, cualquier persona, sea interesado o no, se requiere la publicación del anuncio en el Diario Oficial correspondiente (Estado, Comunidad Autónoma o Provincia), dando la oportunidad de examinar el procedimiento, o parte del mismo, que se acuerde por el órgano competente para resolverlo, siendo preciso señalar el lugar de exhibición y el plazo para formular alegaciones ( art. 83.2 LPA 39/2015), que suele realizarse a través de puntos de acceso en las webs de los departamentos ministeriales.

80 Art. 83.1 de la Ley 39/2015, de 1 de octubre, del Procedimiento Administrativo Común de las Administraciones Públicas.

81 Art. 83.4 de la Ley 39/2015, de 1 de octubre, del Procedimiento Administrativo Común de las Administraciones Públicas. En algunos procedimientos las normas específicas que los regulan establecen que el trámite de audiencia puede tener el carácter de obligatorio por estar así previsto. En esos casos, como es el de las normas urbanísticas, se convierte en un trámite esencial.

82 Informe del grupo Mandelkern sobre mejora de la regulación (2011). Disponible en: http://ec.europa.eu/smart-regulation/better_regulation/documents/mandelkern_report.pdf (consultado el 3 de noviembre de 2017). Epígrafe 4.2.1, séptimo párrafo. 
abiertas y motivadas, a través de un canal público en el que todos puedan conocer las solicitudes de comparecencias y su interés o relación con la materia que se encuentra en estudio o tramitación. En este sentido planteamos que puedan ser las organizaciones cívicas o empresariales las que puedan solicitar ser parte de estos procesos, para favorecer el debate público, siendo la aceptación la regla general, estableciendo la obligación de motivar la negativa.

En esta línea, de llegar a establecer un principio de igualdad de trato, se manifiesta la ley chilena, ya mencionada. En virtud de este principio, aunque los poderes públicos no tienen la obligación de conceder las audiencias solicitadas, si existe un deber de igualdad de trato a los que soliciten audiencias sobre la misma materia. Es decir, si a una persona u organización se le concede una reunión sobre una determinada materia, cualquier podrá solicitar audiencia sobre la misma materia y deberá ser atendido, salvo que la solicitud no cumpla con los requisitos establecidos en la ley y reglamentos.

\section{Las peticiones ciudadanas}

Otra vía para ejercer la participación política sería el derecho de petición. A pesar de su tradición histórica este derecho de petición se viene entendiendo como una institución residual en el derecho actual ya que el avance del Estado de Derecho confiere a los ciudadanos mecanismos jurisdiccionales para la defensa de sus derechos sin que sea necesario acudir a la vía del derecho de petición cuando existe un procedimiento bien en la vía administrativa, bien en la vía jurisdiccional. Sin embargo hay dos elementos que en los últimos años han impulsado el uso de este derecho para la influencia política, que puede ser aprovechado por los grupos de presión.

Por un lado su tardía regulación ${ }^{83}$ y por otro la creación, en el contexto tecnológico actual, de las plataformas de peticiones ciudadanas, desvinculadas de momento de las formas de ejercicio de este derecho que a través de plataformas como Change.org o Avaaz.org, entre otras, permiten al ciudadano una herramienta de participación para reclamar cambios.

El ejercicio de este derecho, tanto para el inicio del procedimiento de elaboración de un anteproyecto de ley, como para la aprobación de reglamentos es susceptible de control judicial. Así lo ha señalado la jurisprudencia del TS cuando señala que no es rechazable de entrada una pretensión de condena a la elaboración y promulgación de un reglamento, que tendrá base cuando haya una obligación legal de dictarlo y cuando la no existencia de la regulación provoque «la implícita creación de una situación jurídica contraria a la Constitución o al ordenamiento jurídico» ${ }^{84}$.

83 LO 4/2001, de 12 de noviembre, reguladora del Derecho de Petición.

84 SSTS de 14 de diciembre de 1998, de 16 de enero de 1998, de 23 de enero de 1998 o 28 de junio de 2004 . 
Hoy en día, la tecnología ha permitido que determinados poderes ejecutivos como el gobierno norteamericano o el británico hayan creado plataformas web que, además de permitir realizar dichas peticiones y adherirse a las mismas, las convierte en públicas. En los lugares en los que no existen este tipo de herramientas ha sido la sociedad civil la que ha organizado campañas de correos electrónicos e, incluso, plataformas que han buscado hacer más sencillo y eficaz el uso del derecho de petición.

Para facilitar que el ejercicio de este derecho se transforme en una práctica más común y eficaz mejorando los flujos, reduciendo los tiempos y facilitando los procedimientos sería necesario también flexibilizar las formas de presentación a través, por ejemplo, de una plataforma online para la presentación y tramitación de las peticiones que permita tanto la publicidad, previa autorización del peticionario, a las peticiones recibidas como la posibilidad de asociarse a peticiones colectivas.

En este sentido se propone que se reformule el proceso para acortar los plazos establecidos de tramitación de las peticiones; se disponga para su uso herramientas tecnológicas para realizar la peticiones de forma telemática, incluyendo la posibilidad de envío a través de una dirección de correo electrónico pública, simplificando el procedimiento de registro; desarrollen la posibilidad de «convocar en audiencia especial a los peticionarios», convocatoria que podría ser considerada obligatoria, al obtener un número determinado de apoyos a la petición.

Desde el punto de vista de la transparencia, los distintos Ministerios deberían proporcionar plataformas para dar publicidad acerca de las peticiones para aquellos casos en los que los ciudadanos, en cumplimiento de la legislación de protección de datos, así lo autoricen, ya sea uno a uno o de manera centralizada. Asimismo, debe publicarse el trámite realizado incluyendo, en su caso, la respuesta recibida con el consentimiento previo del peticionario. Además se podría publicar un informe periódico de las peticiones que recoja no sólo la información numérica de las peticiones tramitadas, sino una información más detallada sobre el curso dado a las mismas, número de apoyos recibidos, respuesta de la administración... Podría incluso plantearse la publicación conjunta de las peticiones recibidas por la $A G E$, a través de una plataforma única, lo que también podría contribuir a la transparencia de las acciones de influencia.

\section{LA DEMOCRATIZACIÓN DEL LOBBY}

Las actividades de influencia forman parte de la democracia desde tiempo inmemorial, sin embargo, el derecho ha optado durante mucho tiempo por evitar su regulación. La crisis de confianza de los ciudadanos en las instituciones ha incluido la regulación de estas actividades en la agenda política.

La regulación se ha planteado desde el inicio, y de una manera generalizada, como una forma de evitar la influencia indebida y su capacidad de afectar a las 
decisiones públicas. De este modo, se ha asumido la actividad del lobby como una labor propia de determinadas elites socio económicas ante la que el Estado de Derecho sólo puede actuar promoviendo su control. Esta postura ha demostrado reiteradamente su ineficacia, víctima de un formalismo incapaz de dar respuesta a la realidad del problema que trata de resolver.

La regulación del lobby no puede limitarse al control, por otro lado imprescindible, de la actuación de unos pocos, sino que debe ofrecer una respuesta general al papel de los actores no institucionales en la toma de decisiones públicas. Desde esta perspectiva, el gran reto del lobby no es su control sino su democratización.

La regulación no debe ceñirse únicamente a evitar la corrupción, sino que debe ir mucho más allá, articulando vías de participación y acceso a los poderes públicos, evitando la influencia indebida y el trato discriminatorio, garantizando el principio de igualdad de participación, «una de las igualdades positivas más importantes de la vida moderna» ${ }^{85}$. De este modo, las medidas para contribuir a la transparencia son indispensables pero insuficientes, por lo que se hace necesario complementarlas con elementos que sirvan para fortalecer la integridad pública y rebajar las barreras de acceso al sistema político, reconociendo el papel del lobby como una forma de participación política de la sociedad.

Por ello, en este trabajo se propone un sistema de regulación no especifico centrado en la transparencia de las actividades de influencia, no dependiente de los grupos que las desarrollan, y que se complemente con una promoción decidida de los instrumentos institucionalizados de participación, facilitando la labor de los distintos actores que pretenden influir sobre el ejercicio de los poderes públicos.

$$
* * *
$$

TITLE: The activity of Lobbies and the Executive: a legal solution further than the registration

ABSTRACT: The Regulation of lobbies has always found many difficulties for definition, application and eficiency. This regulation has been focusing historically on identifying the key actors undertaking lobbying activities and applying transparency to both their organization and their activities. In our opinion, this legislative model, which comes from the American legislation on lobbying of 1946, is inefficient and insufficient as it typically leaves out key actors that undertake lobbying activities. Our preferred option is to regulate this field by focusing on the activities and not on the actors, and to search for means that far from adding more difficulties to the lobbying activity, which converts it into something reserved only for the few with more resources, make it an easy activity for all.

RESUMEN: La regulación de los grupos de presión a lo largo de la bistoria presenta dificultades de definición, de aplicación y de eficacia. Esta regulación se ha centrado bistóricamente en identificar a aquellos que

85 Shapiro, M. «Equality and diversity», European Review of Public Law, vol. 11, núm. 2, 1999, p. 
realizan estas labores de influencia y aplicar la transparencia tanto a su organización como a sus actividades. En nuestra opinión este modelo, hijo de la legislación norteamericana de 1946 es ineficaz e insuficiente, al dejar fuera organizaciones y sujetos que realizan este tipo de actividades. Abogamos por centrar la regulación en las actividades y no en los sujetos que las desarrollan y buscar otros caminos que lejos de dificultar la acción de lobby, que convierte esto en algo reservado a aquellos que cuentan con más recursos, facilite las acciones de influencia a través de instrumentos institucionalizados

KeY Words: Transparency; Lobby; Participation; Information.

Palabras Clave: Transparencia; Grupos de presión; Grupos de interés; Cabildeo; Participación; Información.

FECHA DE RECEPCIÓN: 15.05.2017

FECHA DE ACEPTACIÓN: 26.07.2017 